\title{
ARTICLE
}

Received 26 Oct 2012 | Accepted 31 May 2013 | Published 1 Jul $2013 \quad$ DOl: 10.1038/ncomms3092

\section{Caesium accumulation in yeast and plants is selectively repressed by loss of the SNARE Sec22p/SEC22}

Stephan Dräxl ${ }^{1,2}$, Johannes Müller ${ }^{3,4}$, Wei B. Li ${ }^{5}$, Bernhard Michalke ${ }^{6}$, Hagen Scherb ${ }^{4}$, Burkhard A. Hense ${ }^{4}$, Jochen Tschiersch', Ulrike Kanter ${ }^{2} \&$ Anton R. Schäffner ${ }^{2}$

The non-essential cation caesium $\left(\mathrm{Cs}^{+}\right)$is assimilated by all organisms. Thus, anthropogenically released radiocaesium is of concern to agriculture. $\mathrm{Cs}^{+}$accumulates owing to its chemical similarity to the potassium ion $\left(\mathrm{K}^{+}\right)$. The apparent lack of a $\mathrm{Cs}^{+}$-specific uptake mechanism has obstructed attempts to manipulate $\mathrm{Cs}^{+}$accumulation without causing pleiotropic effects. Here we show that the SNARE protein Sec22p/SEC22 specifically impacts $\mathrm{Cs}^{+}$accumulation in yeast and in plants. Loss of Saccharomyces cerevisiae Sec22p does not affect $\mathrm{K}^{+}$homeostasis, yet halves $\mathrm{Cs}^{+}$concentration compared with the wild type. Mathematical modelling of the uptake time course predicts a compromised vacuolar $\mathrm{Cs}^{+}$deposition in sec224. Biochemical fractionation confirms this and indicates a new feature of Sec22p in enhancing non-selective cation deposition. A developmentally controlled loss-of-function mutant of the orthologous Arabidopsis thaliana SEC22 phenocopies the reduced $\mathrm{Cs}^{+}$uptake without affecting plant growth. This finding provides a new strategy to reduce radiocaesium entry into the food chain.

\footnotetext{
${ }^{1}$ Institute of Radiation Protection, Helmholtz Zentrum München, German Research Center for Environmental Health, 85764 Neuherberg, Germany. ${ }^{2}$ Institute of Biochemical Plant Pathology, Helmholtz Zentrum München, German Research Center for Environmental Health, 85764 Neuherberg, Germany. ${ }^{3}$ Center for Mathematical Sciences, Technische Universität München, 85747 Garching, Germany. ${ }^{4}$ Institute of Computational Biology, Helmholtz Zentrum München, German Research Center for Environmental Health, 85764 Neuherberg, Germany. ${ }^{5}$ Research Unit Medical Radiation Physics and Diagnostics, Helmholtz Zentrum München, German Research Center for Environmental Health, 85764 Neuherberg, Germany. ${ }^{6}$ Research Unit Analytical BioGeoChemistry, Helmholtz Zentrum München, German Research Center for Environmental Health, 85764 Neuherberg, Germany. Correspondence and requests for materials should be addressed to S.D. (email: sjohanndraexl@yahoo.com) or to A.R.S. (email: schaeffner@helmholtz-muenchen.de).
} 
C $\mathrm{s}^{+}$is considered to be non-essential for organisms. As it is the rarest alkali cation that does not accumulate in soil, no detrimental effects are ascribed to $\mathrm{Cs}^{+}$in natural conditions. However, it has acquired enormous ecological importance owing to the anthropogenic release of its persisting radioisotope ${ }^{137} \mathrm{Cs}\left(T_{1 / 2}=30.1\right.$ years), in particular by catastrophic events like the nuclear meltdown and explosions of the Chernobyl or Fukushima nuclear power plants ${ }^{1,2}$. Among the alkali metal cations, $\mathrm{K}^{+}, \mathrm{Rb}^{+}$and $\mathrm{Cs}^{+}$have comparable physico-chemical characteristics owing to similar radii of their hydrated ions ${ }^{3}$. Therefore, $\mathrm{Cs}^{+}$and $\mathrm{Rb}^{+}$uptake is mediated by potassium transport systems and $\mathrm{Cs}^{+}$radioisotopes easily enter the food chain via plants ${ }^{4,5}$. Agriculture in contaminated areas needs to be restricted or remediation strategies have to be developed $^{6}$. Bioremediation could be based on plants accumulating higher amounts of $\mathrm{Cs}^{+}$. Conversely, it has been suggested to reduce $\mathrm{Cs}^{+}$input into the food chain by developing 'safer crops', which discriminate against $\mathrm{Cs}^{+}$(ref. 7). To this end, $\mathrm{Cs}^{+}$uptake has been intensely studied in plants. Uptake and transport across root plasma membranes are considered to be the key aspect and thereby a promising target for manipulating $\mathrm{Cs}^{+}$ uptake $^{5}$. High-affinity $\mathrm{Cs}^{+}$uptake has been attributed to HAK/ KUP-type $\mathrm{K}^{+}$transporters ${ }^{5}$. Low-affinity uptake, although less relevant for ecological scenarios, can be mediated through CNGC-type channels ${ }^{5}$. Mutual interference of $\mathrm{Cs}^{+}$with $\mathrm{K}^{+}$or $\mathrm{Rb}^{+}$accumulation has further substantiated it as a substrate for $\mathrm{K}^{+}$uptake proteins in plants and other organisms ${ }^{5,6,8,9}$.

However, $\mathrm{Cs}^{+}$exhibits toxicity already at a rather low concentration with respect to the high intracellular $\mathrm{K}^{+}$ concentration, whereas $\mathrm{Rb}^{+}$can even replace $\mathrm{K}^{+}$in a potassium-depleted scenario ${ }^{10}$. Previous studies have shown that $\mathrm{Cs}^{+}$may either inhibit or compete with $\mathrm{K}^{+}$-dependent processes, and that $\mathrm{K}^{+}$and $\mathrm{Cs}^{+}$concentrations are not strictly correlated $^{9,11,12}$. Therefore, alternative transport processes may enable a discrimination between these closely related cations. Nevertheless, attempts to specifically manipulate $\mathrm{Cs}^{+}$ accumulation in plants have failed owing to interference with $\mathrm{K}^{+}$homeostasis leading to detrimental, pleiotropic effects ${ }^{5}$. A discriminative uptake mechanism for a non-essential and rare cation would also be surprising from an evolutionary point of view, as toxic concentrations are not reached in nature. Therefore, a biotechnological approach based on mutagenesis should target crucial root uptake and/or export proteins to achieve an improved $\mathrm{K}^{+} / \mathrm{Cs}^{+}$specificity and selectivity ${ }^{5}$. In addition, recent analyses of the natural genetic variation of $\mathrm{Cs}^{+}$ accumulation have revealed several quantitative trait loci in A. thaliana accessions, which might be helpful for determining additional, possibly multigenic, factors in $\mathrm{Cs}^{+}$homeostasis ${ }^{13,14}$.

The yeast $S$. cerevisiae provides a unicellular and simple test system to study $\mathrm{Cs}^{+}$uptake, as it has been shown to utilize cation transporters and channels similar to plant cells ${ }^{8}$. We have recently employed an unbiased approach to identify candidate genes compromising $\mathrm{Cs}^{+}$accumulation by screening a yeastknockout collection ${ }^{15}$. Vacuolar maintenance and vesicle transport are the highest enriched categories among the identified genes. Here, we characterize the mutant $\sec 22 \Delta$ in more detail. It specifically reduces the accumulation of $\mathrm{Cs}^{+}$, as the homeostasis of $\mathrm{K}^{+}$and other cations is not affected. Sec22p is a well-described non-essential yeast SNARE involved in the anterograde and retrograde vesicle membrane fusion at the endoplasmic reticulum (ER)-Golgi interface and in autophagy ${ }^{16,17}$. Modelling of $\mathrm{Cs}^{+}$uptake time course points to vacuolar sequestration as a crucial factor, which is compromised in the sec22 4 mutant and thereby indicating a novel feature of Sec22p function in yeast. Although the A. thaliana ortholog SEC22 had been shown to be required for gametophyte development ${ }^{18}$, we succeeded in identifying a sec22 mutant allele, which only affected vegetative tissues and phenocopied the specific repression of $\mathrm{Cs}^{+}$accumulation. The plant gene partially complements the yeast mutant indicating a conserved mechanism. We therefore propose that this novel Sec22p/ SEC22-dependent function will provide a new route to generate 'safer crops'.

\section{Results}

$\mathrm{Cs}^{+}$accumulation is specifically reduced in sec 224 . Previously, we have screened a loss-of-function mutant collection of S. cerevisiae for altered uptake of $\mathrm{Cs}^{+}$(ref. 15). The categories 'vacuolar function' and 'vesicle-mediated transport' are enriched among the mutants that show reduced $\mathrm{Cs}^{+}$concentration. Three of these mutants, vps354, aps3 4 and apl4A, do not significantly affect the $\mathrm{K}^{+}$content $^{15}$. However, we have found that all of them exhibited pleiotropic effects (Supplementary Fig. S1). Therefore, we have considered further candidates with reduced $\mathrm{Cs}^{+}$uptake searching for both a non-pleiotropic behaviour and the existence of homologous genes, which would allow a potential functional analysis in plants. Among them, sec22 $\Delta$ exhibits wild-type-like growth and viability (Supplementary Fig. S1). Furthermore, Sec22p-like proteins are conserved in higher organisms including plants (Supplementary Fig. S2a). ${ }^{134}$ Cs tracer studies confirm that $\sec 22 \Delta$ accumulates less than half of $\mathrm{Cs}^{+}$as compared with the wild type (Fig. 1a). In contrast, the potassium analogue $\mathrm{Rb}^{+}$accumulates to similar concentrations. The concentrations of essential cations $\left(\mathrm{K}^{+}, \mathrm{Na}^{+}, \mathrm{Ca}^{2+}\right.$ and $\mathrm{Mg}^{2+}$ ) remain unaltered. Complementation with the wild-type gene suppresses this $\mathrm{Cs}^{+}$-discriminative phenotype (Fig. 1a,b). Thus, the loss of SEC22p (YLR268Wp) does not disturb growth and viability, but specifically reduces $\mathrm{Cs}^{+}$concentration without affecting the content in $\mathrm{K}^{+}$and other essential cations. In contrast to the lower $\mathrm{Cs}^{+}$accumulation, $\sec 22 \Delta$ displays a slightly increased sensitivity towards $\mathrm{Cs}^{+}$(Fig. 1d).

Interestingly, wild-type yeast cells accumulate $\mathrm{Cs}^{+}$following a two-phase kinetics distinct from the hyperbolic uptake described for $\mathrm{K}^{+} / \mathrm{Rb}^{+}$(ref. 19). The uptake of $\mathrm{Cs}^{+}$comprises an initial step reaching about $0.35 \mathrm{mM}$ at $2-3 \mathrm{~h}$ and a second step reaching a plateau at $2.2 \mathrm{mM}$ cellular $\mathrm{Cs}^{+}$after $>16 \mathrm{~h}$ (Fig. $2 \mathrm{a}$ ). The time course of $\sec 22 \Delta \mathrm{Cs}^{+}$accumulation is highly similar to that of the wild type during the initial phase of about $2.5 \mathrm{~h}$ (Fig. 2a-c). However, further uptake is repressed and a lower steady-state concentration of $\sim 1.1 \mathrm{mM} \mathrm{Cs}^{+}$is reached (Fig. $2 \mathrm{~b}$ ).

Modelling proposes impaired vacuolar $\mathrm{Cs}^{+}$deposition in $\sec 224$. To gain further understanding of the $\mathrm{Cs}^{+}$uptake and how sec $22 \Delta$ leads to the lower $\mathrm{Cs}^{+}$accumulation, we have developed a mathematical model to describe the time course of wild-type and mutant high-affinity $\mathrm{Cs}^{+}$uptake. $\mathrm{Cs}^{+}$has been shown to be deposited into the vacuole of yeast cells ${ }^{8}$. Therefore, a minimal model comprises three compartments with defined volumes, the extracellular medium $\left(V_{1}\right)$, the cytoplasm $\left(V_{2}\right)$ and the vacuole $\left(V_{3}\right)$. Cellular and vacuolar volumes have been microscopically determined to be $\sim 35 \mathrm{fl}$ and $9 \mathrm{fl}$, respectively, and thus the cytoplasmic volume $V_{2}$ should be $26 \mathrm{fl}$. The respective volumes do not significantly differ between wild type and mutant (Fig. 3a). Two inward and outward fluxes into and from the cytoplasm (with rate constants $k_{1}$ and $k_{2}$, respectively), as well as further possible sequestration into and from the vacuole (with rate constants $k_{3}$ and $k_{4}$, respectively), with a linear dependence on $\mathrm{Cs}^{+}$concentrations are assumed (Supplementary Fig. S3). In addition, the model allows for a potential delay of the vacuolar deposition by introducing a time-dependent upregulation $s(t)$ of the flux towards the internal compartment. 


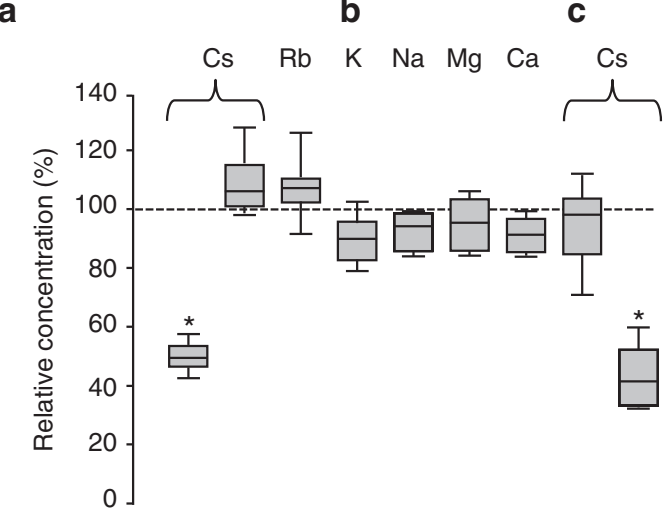

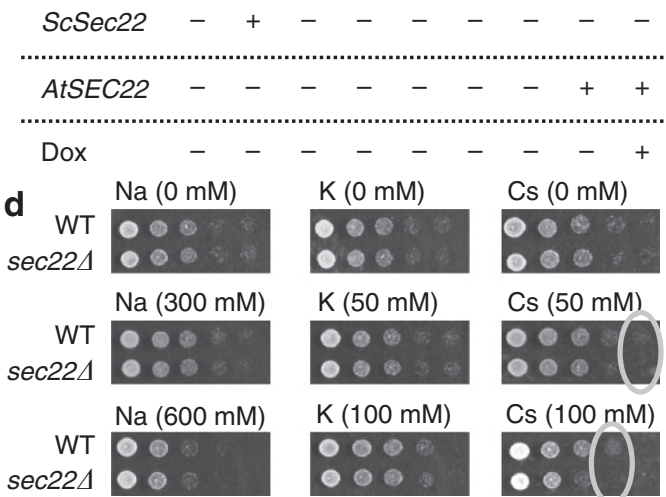

Figure 1 | $\mathrm{Cs}^{+}$-specific repression of cation accumulation in the yeast mutant sec22 $\triangle$. (a) $\mathrm{Cs}^{+}$and $\mathrm{Rb}^{+}$uptake by the sec22 $\triangle 4$ mutant and a complemented strain $(\mathrm{ScSec} 22+) .{ }^{134} \mathrm{Cs}$ and ${ }^{86} \mathrm{Rb}$ cation concentrations were determined from $10^{7}$ cells after $18 \mathrm{~h}$ in YPD containing $50 \mu \mathrm{M}$ 5-FU and $50 \mu \mathrm{M} \mathrm{CsCl}$. The wild-type reference strain BY4741 contained $2.1 \pm 0.1 \mathrm{mMCs}^{+}$or $2.3 \pm 0.6 \mathrm{mM} \mathrm{Rb}^{+}$. (b) $\mathrm{K}^{+}, \mathrm{Na}^{+}, \mathrm{Ca}^{2+}$ and $\mathrm{Mg}^{2+}$ concentrations were retained in the sec 224 mutant under these conditions. Wild-type concentrations were $164 \pm 9.7 \mathrm{mM} \mathrm{K}^{+}, 2.7 \pm 0.1 \mathrm{mM} \mathrm{Na}^{+}$ $31.4 \pm 0.3 \mathrm{mM} \mathrm{Mg}^{2+}$ and $1.2 \pm 0.1 \mathrm{mM} \mathrm{Ca}^{2+}$. (c) Complementation of sec22 $\triangle \mathrm{Cs}^{+}$uptake deficiency by $A$. thaliana SEC22 expressed under the control of a doxycycline-repressible promoter. Presence or absence of $S$. cerevisiae Sec22 or A. thaliana SEC22 expression, as well as addition of doxycycline, is indicated by $+/-$. (a-c) Box plots are displayed $(n=10)$; quartiles define the box limits and antennas denote maximum and minimum values; asterisks indicate significant differences from wild type $(P \leq 0.001, t$-test). (d) Toxicity test of wild type and sec224 in dilution series $(1 / 1,1 / 5,1 / 25,1 / 125$ and $1 / 625)$ at different concentrations of alkali cations in YPD agar pH 6. Grey circles indicate dilutions at which sec22 4 shows higher sensitivity than wild type. Colony sizes, $7-8 \mathrm{~mm}$.

A deterministic model consisting of ordinary differential equations for the time dependence of the cellular $\mathrm{Cs}^{+}$ concentration $\operatorname{tot}(t)$ has been developed. This model allows for fitting the experimental data, as well as for predicting cytoplasmic $x(t)$ and vacuolar $y(t) \mathrm{Cs}^{+}$concentrations as expressed by the following equations (Fig. 2a-c; Supplementary Methods):

$$
\begin{aligned}
x(t) & =\frac{\left(V_{2}+V_{3}\right)(1-\tau)}{V_{3} \tau s(t)+V_{2}(1-\tau)} \operatorname{tot}(t), \\
y(t) & =\frac{\left(V_{2}+V_{3}\right) \tau s(t)}{V_{3} \tau s(t)+V_{2}(1-\tau)} \operatorname{tot}(t),
\end{aligned}
$$

with

$$
\frac{d[\operatorname{tot}(t)]}{d t}=k_{1} \frac{V_{2}}{\left(V_{2}+V_{3}\right)} c(0)-\left(N \frac{V_{2}}{V_{1}} k_{1}+\frac{V_{2}(1-\tau)}{V_{3} \tau s(t)+V_{2}(1-\tau)} k_{2}\right) \operatorname{tot}(t),
$$

$\tau=k_{3} / \Gamma=1-k_{4} / \Gamma, \quad \Gamma=k_{3}+k_{4}, c(0)=50 \mu \mathrm{M}$ and the Hill function $s(t)=t^{n} /\left(\right.$ thresh $\left.^{n}+t^{n}\right)$.

For wild type, the model predicts a rapid increase of the cytoplasmic $\mathrm{Cs}^{+}$concentration with well-defined rate constants $k_{1}$ and $k_{2}$, and a delayed sequestration to the vacuole with large, but less assessable, rate constants (Supplementary Table S1; Supplementary Methods). Fitting the wild-type experimental data, the model estimates $\mathrm{Cs}^{+}$concentrations of $0.4 \mathrm{mM}$ in the cytoplasm and of $7.1 \mathrm{mM}$ in the vacuole at the saturation of $\mathrm{Cs}^{+}$ uptake (Fig. 2a). Fitting the sec22 4 mutant data results in an insignificantly altered rate constant $k_{1}(P \approx 1)$, an only slightly changed $k_{2}(P=0.02)$ and again a delayed sequestration to the vacuole (Supplementary Tables S1, S2 and S4). However, in contrast to the wild type, the model predicts a significantly compromised deposition of $\mathrm{Cs}^{+}$to sec224 vacuoles reaching only $3.2 \mathrm{mM}$ (indicated by $P(\tau)=1.15 \times 10^{-11}$ ) at a cytosolic $\mathrm{Cs}^{+}$concentration similar to wild type (Fig. 2a,b; Supplementary Table S1). Thus, the model indicates that the observed sec224 phenotype results from reduced vacuolar $\mathrm{Cs}^{+}$deposition.

Reduced $\mathrm{Cs}^{+}$accumulation in $\sec 22 \Delta$ vacuoles validates model. To test the predictions of the mathematical model on vacuolar $\mathrm{Cs}^{+}$deposition, $\mathrm{Cs}^{+}$-laden vacuoles have been isolated from wild-type and mutant cells, and the sequestered portions of $\mathrm{Cs}^{+}$relative to whole-cell lysates have been measured. Wild-type and mutant cells contain similar amounts of the secretory systemindependent vacuolar marker $\alpha$-mannosidase in yeast ${ }^{20}$, which has been used to normalize the $\mathrm{Cs}^{+}$analyses (Supplementary Fig. S4). The total $\mathrm{Cs}^{+}$taken up into wild-type cells ( 75 amol per cell at a concentration of $2.1 \mathrm{mM}$ ) is partitioned to the cytoplasm at a concentration of $0.78 \mathrm{mM}$ and to the vacuole at $6.9 \mathrm{mM}$. Accordingly, $\sim 82 \%$ of the total $\mathrm{Cs}^{+}$is deposited into the vacuole (Fig. 2d). This high recovery of $\mathrm{Cs}^{+}$also indicates that potential losses during the isolation procedure have been successfully avoided. The number is also in agreement with previous analyses of $\mathrm{Cs}^{+}$compartmentation $^{21}$, but nevertheless may represent a lower limit of the vacuolar content. In contrast, sec224 (39 amol per cell; $1.1 \mathrm{mM}$ ) shows a cellular compartmentation of $0.66 \mathrm{mM}$ $\mathrm{Cs}^{+}$in the cytoplasm and $2.4 \mathrm{mM}$ in the vacuole. The potassium analogue $\mathrm{Rb}^{+}$is similarly partitioned to cytoplasm and vacuole of wild-type and mutant cells (Fig. 2e). Thus, the general reduction of $\mathrm{Cs}^{+}$accumulation by $\sec 22 \Delta$ is owing to a specifically compromised partitioning to the vacuole, which contains only about one-third of the wild-type amount ( $22 \mathrm{amol}$ per cell in comparison to $62 \mathrm{amol}$ in wild type). This result is in good agreement with the predictions of the mathematical model (Fig. 2a,b). The reduction of $\mathrm{Cs}^{+}$uptake is not owing to a decrease in vacuolar volume or cell size, as both are not differentially influenced in wild-type and mutant cells after incubation in $\mathrm{Cs}^{+}$-containing YPD medium (Fig. 3a,b). In contrast, Jorgensen et al. ${ }^{22}$ have reported an even slightly increased median cell size of $\sec 224$. However, we have observed a higher frequency of cells harbouring several smaller vacuoles in the mutant, which is not evident in cells grown without $\mathrm{Cs}^{+}$ (Fig. 3c,d). Thus, there is a $\mathrm{Cs}^{+}$-dependent morphological effect on $\sec 22 \Delta$ vacuoles.

The model also suggests that the reduced $\mathrm{Cs}^{+}$uptake of $\sec 224$ does not depend on differences at the plasma membrane (Supplementary Table S1). We have addressed this issue by recording the loss of $\mathrm{Cs}^{+}$tracer from $\mathrm{Cs}^{+}$-laden cells at 

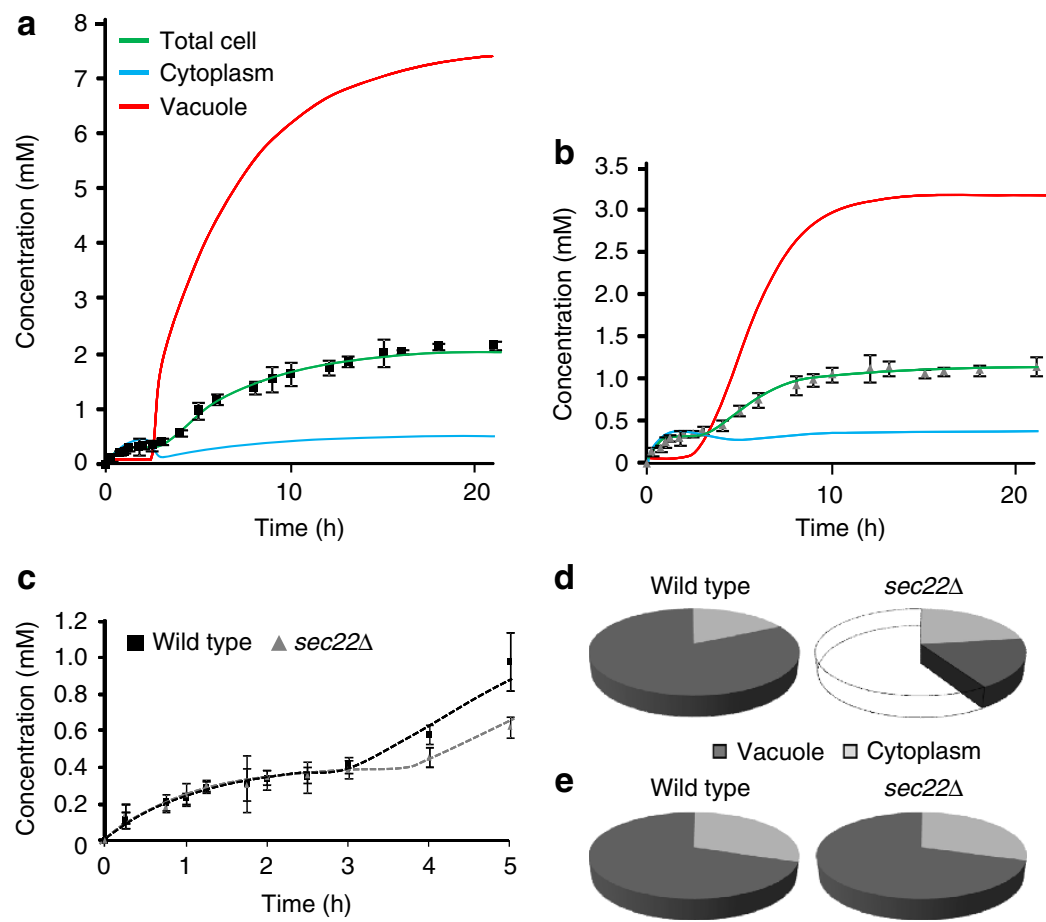

Figure 2 | Time course of $\mathbf{C s}^{+}$accumulation in wild-type and sec22 4 -mutant yeast. Whole-cell $\mathrm{Cs}^{+}$concentrations were recorded at the indicated times after the addition of $50 \mu \mathrm{M} \mathrm{CsCl}$. (a) Wild-type time course. (b) sec22 time course. Note the different scale of the concentration in (a) and (b). Continuous lines represent the fitting of the experimental data by the mathematical modelling and the predictions for the compartmentalization: the total intracellular (green), the cytoplasmic (blue) and the vacuolar (red) concentrations are depicted (Supplementary Methods). Steady-state Cs ${ }^{+}$ concentrations were predicted at $2.1 \mathrm{mM}$ (wild type) or $1.1 \mathrm{mM}(\mathrm{sec} 224$ ) in whole cells, at $0.40 \mathrm{mM}$ (wild type) or $0.39 \mathrm{mM}$ (sec224) in the cytoplasm, and at $7.1 \mathrm{mM}$ (wild type) or $3.2 \mathrm{mM}$ (sec224) in vacuoles. (c) Overlay of the initial time courses of wild type and sec22 . (a-c) Data are presented as means \pm s.d. $(n=10)$. (d) Scheme of relative $\mathrm{Cs}^{+}$compartmentalization in wild type and sec224. Total $\mathrm{Cs}^{+}$accumulation and vacuolar $\mathrm{Cs}^{+}$ compartmentalization were determined from whole cells after $18 \mathrm{~h}$ incubation in YPD supplemented with $50 \mu \mathrm{M}$ radiolabelled $\mathrm{Cs}^{+}$. One complete pie represents $75 \mathrm{amol} \mathrm{Cs}^{+}$per cell (complete uptake of wild-type cells). Total amount and vacuolar partitioning of Cs ${ }^{+}$had been measured and were related to equal activity of the vacuolar marker $\alpha$-mannosidase, resulting in a vacuolar $\mathrm{Cs}^{+}$deposition of $\sim 82 \%$ (wild type) and $55 \%$ (sec 224 ), respectively; $n=3$ independent vacuole isolations. (e) Scheme of relative $\mathrm{Rb}^{+}$compartmentation measured in parallel to $\mathrm{Cs}^{+}$distribution. The complete pie represents $81 \mathrm{amol}$ per cell (wild type) and $87 \mathrm{amol}$ per cell (sec224). $\mathrm{Rb}^{+}$deposition to the vacuole (70\%) was identical for wild type and sec224; $n=3$.

equilibrium conditions for $2 \mathrm{~h}$ after substituting the external tracer by unlabelled $\mathrm{Cs}^{+}$. The initial rate of efflux from wild-type and mutant cells at $t=0 \mathrm{~h}$ was $0.62 \pm 0.11 \mathrm{mMh}^{-1}$ and $0.52 \pm 0.09 \mathrm{mMh}^{-1}$, respectively. Thus, the efflux is not significantly altered in $\sec 22 \Delta \quad(P=0.34$; Supplementary Fig. S5). The magnitudes of the modelled efflux rates (wild type: $1.2 \mathrm{~h}^{-1} \times 0.40 \mathrm{mM}=0.48 \mathrm{mMh}^{-1} ; \sec 224: 1.9 \mathrm{~h}^{-1} \times 0.39 \mathrm{mM}=$ $0.74 \mathrm{mMh}^{-1}$ ) (Fig. 2a; Supplementary Table S1) are in agreement with these experimentally determined values. In summary, these results are in accordance with the prediction of similar $\mathrm{Cs}^{+}$fluxes at the plasma membrane in wild type and $\sec 22 \Delta$.

$\mathrm{Cs}^{+}$uptake of cation transport mutants differs from sec22 . $^{+}$ To further explore and validate the results on the repressed Cs ${ }^{+}$ accumulation and vacuolar sequestration in $\sec 22 \Delta$, additional mutants with known defects in cation import and export have been employed to analyse their impact on $\mathrm{Cs}^{+}$uptake. The time course of $\mathrm{Cs}^{+}$uptake has been recorded for $\operatorname{trk} 1 \Delta, \operatorname{trk} 2 \Delta$ and trk1 $\Delta$ trk2 $\Delta$, as well as for ena1-4A. The high-affinity transporter Trk1 $\mathrm{p}$ and its homologue Trk2p are involved in potassium uptake at the plasma membrane; the Enal-4 gene cluster encodes ATPases related to cation efflux ${ }^{23,24}$. In all cases except trk24, the uptake time courses of these mutants primarily affecting the cation transport at the plasma membrane are considerably different from the respective wild types and, importantly, from $\sec 22 \Delta$ (Figs 2 and 4 ). Thus, these analyses support the divergent role of Sec $22 \mathrm{p}$ in $\mathrm{Cs}^{+}$accumulation.

The mutant $t r k 1 \Delta$ leads to an attenuated increase in $\mathrm{Cs}^{+}$and a longer initial phase until further accumulation reaches almost wild-type level after $18 \mathrm{~h}$, whereas the uptake trajectory of trk $2 \Delta$ is almost indistinguishable from wild type (Fig. 4a). Thus, this data clearly demonstrate that (i) Trk1p is involved in $\mathrm{Cs}^{+}$uptake and (ii) $\operatorname{Trk} 2 \mathrm{p}$ does apparently not contribute as long as Trk1p or other mechanisms are effective. However, the combined presence of $\operatorname{Trk} 1 \mathrm{p}$ and $\operatorname{Trk} 2 \mathrm{p}$ is required for efficient $\mathrm{Cs}^{+}$uptake, as within the time course analysed $\mathrm{Cs}^{+}$accumulation is drastically

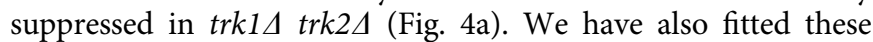
uptake data using the mathematical model described above, yet employing the knowledge on the specific defects of trk $1 \Delta$ and trk2 $\Delta$ in cation influx by assuming an unchanged wild-type-like efflux at the plasma membrane. In all cases, the predicted $\mathrm{Cs}^{+}$ sequestration to the vacuole is similar. The modelled influx rate constants $k_{1}$ are unaltered for trk2 $\Delta$, but slightly reduced for trk1 $\Delta$ and strongly repressed for $\operatorname{trk} 1 \Delta$ trk2 $\Delta$ (Supplementary Table S3).

Interfering with plasma membrane cation efflux through the ena1-44 mutant leads to a strongly accelerated $\mathrm{Cs}^{+}$uptake and the apparent loss of the initial phase of the wild-type time course. However, a steady-state $\mathrm{Cs}^{+}$concentration similar to wild type is reached, although at an earlier time point (Fig. 4b). This experiment clearly supports a physiological role of Ena1-4p in 


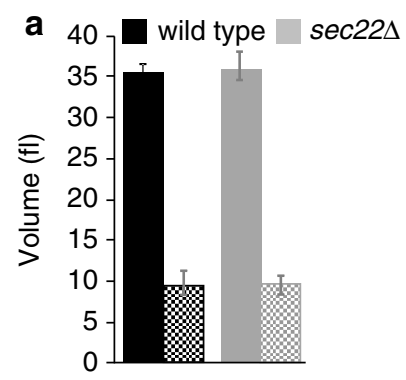

C

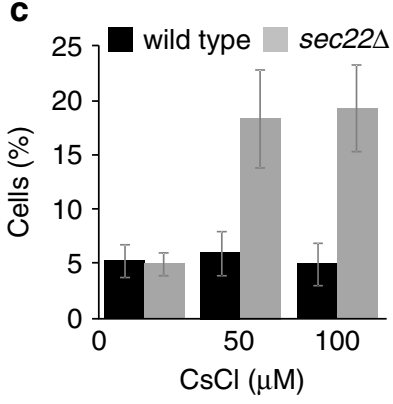

e

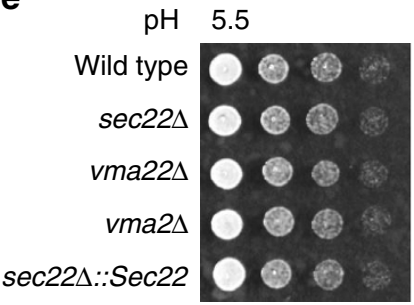

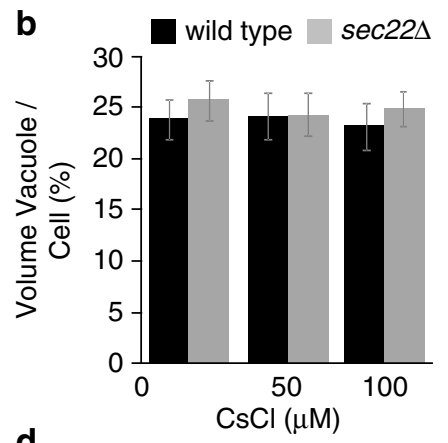

d

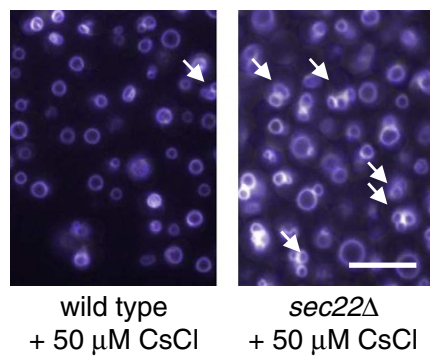

Figure 3 | Characterization of sec22 4 vacuoles. Morphology of vacuoles and pH sensitivity were analysed in sec22 4 and wild type. (a) Cellular (filled bars) and vacuolar (squares) volumes. In case of several vacuolar lobes stained per cell, the volumes of the lobes were added. Cell volumes are $35.2 \pm 1.2 \mathrm{fl}$ (wild type) and $35.8 \pm 1.7 \mathrm{fl}(\sec 224$ ); and vacuolar volumes are $8.8 \pm 0.9 \mathrm{fl}$ and $9.0 \pm 1.2 \mathrm{fl}$. FM4-64 staining was used to label vacuoles in living yeast cells. Fifty cells from three independent cultivations were evaluated. Data are presented as means \pm s.d. (b) Percent ratio of vacuolar to cellular volumes at different external $\mathrm{Cs}^{+}$concentrations $(n=30$ cells). Data are presented as means \pm s.d. (c) Cells with fragmented vacuoles at three different concentrations of external $\mathrm{CsCl}$, as well as at $100 \mathrm{mM}$ external $\mathrm{KCl}$. Cells showing two to five smaller sized lobes were defined as fragmented in contrast to a regular anatomy with a single, large vacuole. Data are presented as means \pm s.d. ( $n=3$ with 100 cells in each independent replicate). All analyses in $(\mathbf{a}, \mathbf{b}, \mathbf{c})$ were performed in YPD-rich medium after addition of cytostatic 5-FU. Both the absolute and relative vacuolar volumes, as well as vacuolar morphology, were similar in wild type and sec22 4 . However, at experimental conditions $\left(50 \mu \mathrm{M} \mathrm{Cs}^{+}\right) \sec 22 \Delta$ has a significantly higher percentage of fragmented vacuoles $(18.3 \pm 4.5 \%)$ than wild type $(6.0 \pm 2.1 \%)(P \leq 0.01)$, which has also been confirmed at $100 \mu \mathrm{M} \mathrm{Cs}{ }^{+}$. (d) Wild-type and mutant cells grown in the presence of $50 \mu \mathrm{M} \mathrm{CsCl}$. Normal and fragmented (white arrows) vacuoles are visualized by FM4-64 fluorescence. Scale bar: $10 \mu \mathrm{m}$.

(e) $\mathrm{pH}$ sensitivity of yeast strains. Wild type, sec224, vma224, vma24 and $\sec 22 \Delta:: \operatorname{Sec} 22(\sec 22 \Delta$ complemented with wild-type Sec22) were tested on YPD plates buffered at different $\mathrm{pH}$ (dilution series $1 / 1,1 / 5,1 / 25,1 / 125$ and 1/325). Colony sizes, 7-8 mm.
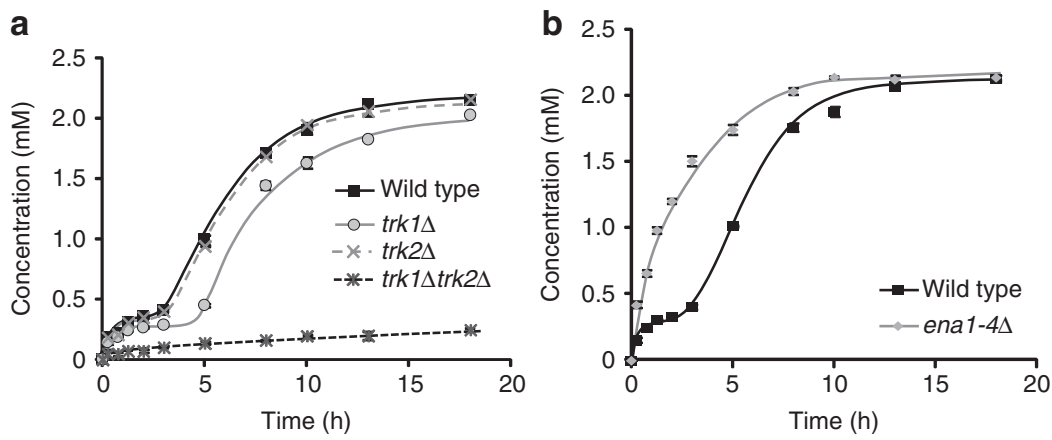

Figure 4 | Time course of $\mathbf{C s}^{+}$accumulation in cation import- and export-impaired mutant yeast strains. The time course of whole-cell $\mathrm{Cs}^{+}$ concentrations have been recorded at the indicated times after the addition of $50 \mu \mathrm{M} \mathrm{CsCl}$ to mutants affecting cation transport at the plasma membrane and their corresponding wild types. $(\mathbf{a}, \mathbf{b})$ Data are presented as means \pm s.d. $(n=10)$. Continuous lines represent the fitting of the cellular $\mathrm{Cs}^{+}$ concentrations by the mathematical model (Supplementary Methods). (a) Time course of trk1 $\Delta$, trk2 $\Delta$ and trk1 trk2 $\Delta$ and their corresponding wild type. (b) Time courses of ena1-4A and its corresponding wild type. 
$\mathrm{Cs}^{+}$efflux at the plasma membrane; its loss allows a more rapid $\mathrm{Cs}^{+}$accumulation. Fitting these data with the mathematical model, in this case assuming an intact, wild-type-like influx rate constant $k_{1}$, predicts a reduced rate $k_{2}$ in accordance with the proposed biological function of Ena1-4p (Supplementary Table S4). In addition, the limitation to wild-type-like steady-state $\mathrm{Cs}^{+}$concentration suggests that the ena1-44 mutation should also have other unknown consequences apart from an effect on the plasma membrane efflux.

SEC22 in A. thaliana affects $\mathrm{Cs}^{+}$accumulation. We employed the model plant $A$. thaliana to investigate whether the sec22 $\Delta$ dependent repression of $\mathrm{Cs}^{+}$uptake in a unicellular eukaryote would also be observed in a higher plant. SEC22 (At1g11890) encodes a protein with $36 \%$ identity at the amino-acid level when compared with yeast Sec22p, sharing all functional domains (Supplementary Fig. S2b). It has been characterized as a SNARE involved in the anterograde vesicle traffic at the ER to Golgi interface $^{25}$. In contrast to its $S$. cerevisiae ortholog, A. thaliana SEC22 is essential, as it is required for gametophyte development ${ }^{18}$. However, we have succeeded in recovering a fully viable and fertile, developmentally controlled loss-offunction mutant allele sec22-3 containing a T-DNA insertion in the 5'-UTR of At1g11890 (SALK_042819; Fig. 5a and Fig. 6). Reverse transcription PCR (RT-PCR) analyses reveal that this allele selectively lacks functional transcripts in vegetative tissue (root, stem and leaves), but retains expression in reproductive

a SALK_042619/sec22-3 At1g11890

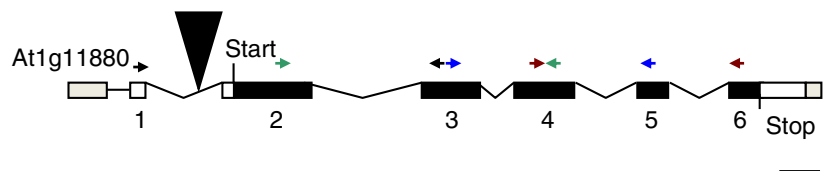

Amplicons: Exon 1-3 Exon 2-4 Exon 3-5 Exon 4-6 $10 \overline{100 \mathrm{bp}}$

b

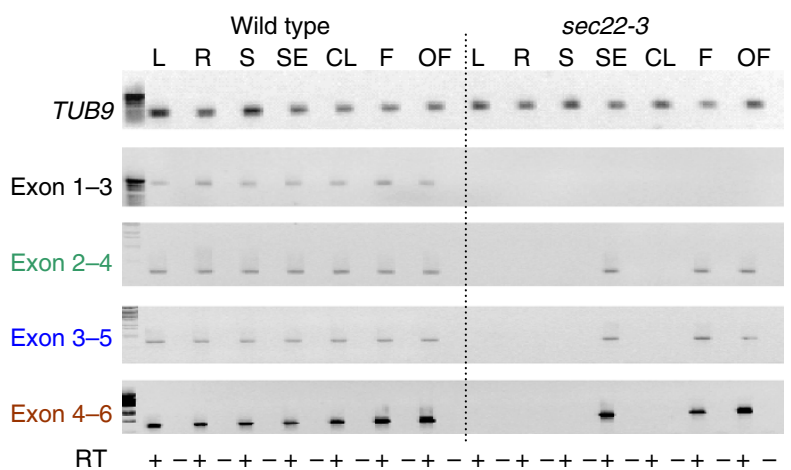

Figure 5 | Developmentally controlled loss of SEC22 transcription in sec22-3. (a) The genomic structure of At 1911890 is schematically shown including the position of the T-DNA insertion in the sec22-3 allele (SALK_042619). Coloured arrows indicate forward and reverse primers used to amplify the marked exon combinations by RT-PCR. (b) RT-PCRbased analysis of SEC22 transcription in wild-type and sec22-3 leaves (L), roots $(R)$, stems $(S)$, one-week-old seedlings $(S E)$, cauline leaves $(C L)$, flowers at stage 7-9 (F) and open flowers (OF, stage 14, with silique in early stage $)^{60}$. Four different SEC22 exon combinations as defined in (a) were probed. A. thaliana TUB9 transcription was used as a positive control; all combinations were tested $+/$ - reverse transcriptase. pUC19 cut by Msp I (for TUB9 and exon 1-3) or $\lambda$ DNA cut by Hin dlll were used as size markers (at the left); amplicon sizes: TUB9, 184 bp; exon 1-3, 350 bp; exon 2-4, $410 \mathrm{bp}$; exon 3-5, $318 \mathrm{bp}$; and exon 4-6, $256 \mathrm{bp}$. organs and young tissue probably due to a cryptic promoter activity of the T-DNA insert (Fig. 5b). The sec22-3 mutant has been examined for altered $\mathrm{Cs}^{+}$accumulation. It is reduced to about one half of wild-type concentration in rosette leaves and by about one-third in roots, while the $\mathrm{Rb}^{+}, \mathrm{K}^{+}, \mathrm{Na}^{+}, \mathrm{Mg}^{2+}$ and $\mathrm{Ca}^{2}+$ contents remain unaltered (Fig. 7). Complementation with wild-type Arabidopsis SEC22 suppresses the phenotype. This demonstrates that the results obtained with yeast $\sec 22 \Delta$ are phenocopied by the plant mutant suggesting a similar functional involvement in $\mathrm{Cs}^{+}$enrichment. To address this equivalence, Arabidopsis SEC22 has been cloned in a doxycycline-repressible expression vector (Supplementary Methods) and transiently expressed in the yeast mutant sec22 2 . Arabidopsis SEC22 is able to revert the low $\mathrm{Cs}^{+}$accumulation of $\sec 22 \Delta$ reaching $\sim 85 \%$ of the wild-type level. This reversion is abolished by suppressing the transgene expression with doxycycline (Fig. 1c). Thus, the plant SEC22 gene is able to functionally complement the yeast $\sec 224$ mutant.

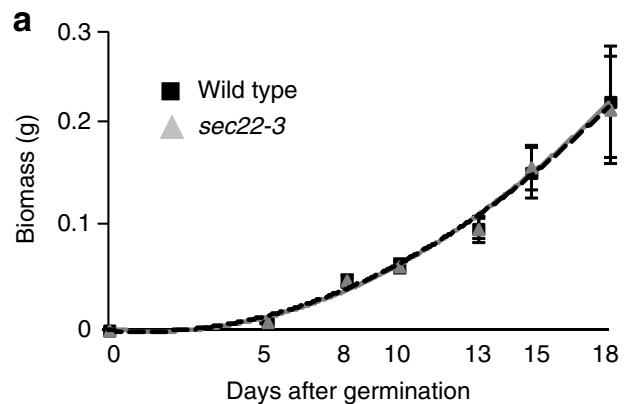

b
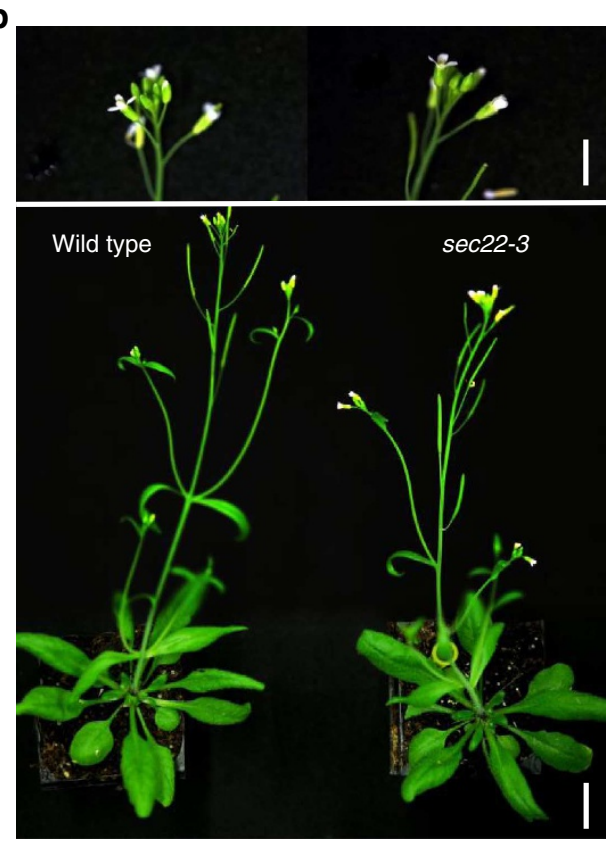

Figure 6 | Growth of $\boldsymbol{A}$. thaliana wild type and sec22-3. (a) Plant development was quantified by measuring biomass (fresh weight) of aerial parts at the indicated time points $(n \geq 15)$. Fresh weight to dry weight ratio was $12.1 \pm 1.8$ for the wild type and $11.6 \pm 2.2$ for $\sec 22-3(n=6)$. Germination rates were identical on soil $(86 \% \pm 2 \%$ in wild type and $88 \% \pm 2 \%$ in sec $22-3$ ) as well as in hydroponic culture (100\% in wild type and $95 \% \pm 2 \%$ in sec22-3). Data are presented as means \pm s.d.; $n \geq 20$.

(b) The mutant did not reveal obvious developmental defects in comparison with wild type; in particular, flower development was not altered. Size bars: upper panel $0.5 \mathrm{~cm}$; lower panel $2 \mathrm{~cm}$. 


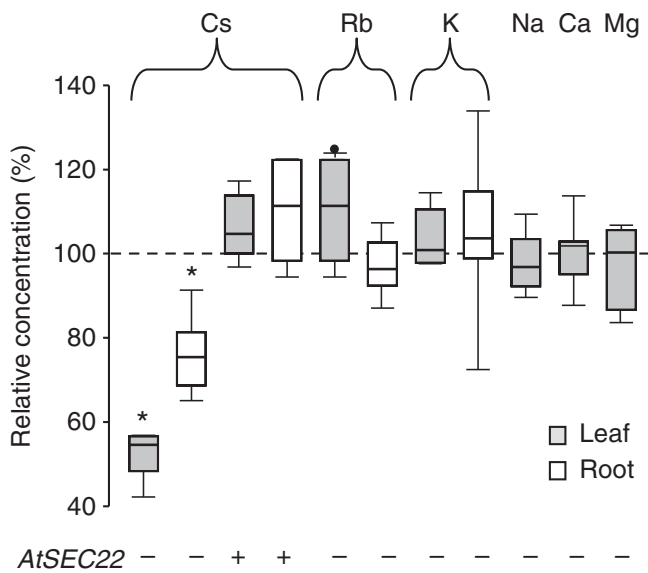

Figure 7 | Cation phenotype of the $\boldsymbol{A}$. thaliana insertion mutant sec22-3. $\mathrm{Cs}^{+}$and $\mathrm{Rb}^{+}$accumulation in leaves and roots of 20-day-old wild-type and sec22-3 plants were analysed in tracer uptake experiments; amounts are related to fresh weight. $\mathrm{K}^{+}, \mathrm{Na}^{+}, \mathrm{Ca}^{2+}$ and $\mathrm{Mg}^{2+}$ contents were measured by atomic emission spectroscopy and referred to dry weight. The fresh weight to dry weight ratio was not different between wild type and sec22-3 (Fig. 6). Hundred percent correspond to $107 \pm 8.2 \mathrm{nmol} \mathrm{Cs}^{+}$ $\mathrm{g}^{-1}$ shoot (rosette); $43 \pm 6.6 \mathrm{nmol} \mathrm{Cs}^{+} \mathrm{g}^{-1}$ root; $158 \pm 7.7 \mathrm{nmol} \mathrm{Rb}^{+} \mathrm{g}^{-1}$ shoot; $53 \pm 7.4 \mathrm{nmol} \mathrm{Rb}^{+} \mathrm{g}^{-1}$ root; $1.3 \pm 0.4 \mathrm{mmol} \mathrm{K}^{+} \mathrm{g}^{-1}$ shoot; $0.62 \pm 0.08 \mathrm{mmol} \mathrm{K}^{+} \mathrm{g}^{-1}$ root; $0.2 \pm 0.003 \mathrm{mmol} \mathrm{Na}^{+} \mathrm{g}^{-1}$ shoot; $0.15 \pm 0.01 \mathrm{mmol} \mathrm{Ca}{ }^{2+} \mathrm{g}^{-1}$ shoot; and $0.3 \pm 0.01 \mathrm{mmol} \mathrm{Mg}^{2+} \mathrm{g}^{-1}$ shoot ( $n \geq 5$, each replicate consisting of at least six plants). Box plots with upper/lower quartiles, minimal and maximal values (antennas), and one outlier (black dot) are shown; asterisks indicate significant differences from wild type ( $P \leq 0.001, t$-test). The expression of AtSEC22 is indicated as + (complemented line) or - (mutant).

\section{Discussion}

The chemical similarity of the non-essential alkali cation $\mathrm{Cs}^{+}$ with the essential $\mathrm{K}^{+}$is a major obstacle for genetic attempts to manipulate radiocaesium accumulation and to prevent it from entry into the food chain $5,6,9$. In this study, however, we demonstrate that specific discrimination against $\mathrm{Cs}^{+}$is possible in the yeast $\sec 22 \Delta$ mutant, while other cations including $\mathrm{K}^{+}$are retained at wild-type levels. Surprisingly, the loss of the orthologous A. thaliana SEC22 expression in vegetative tissues also specifically lowered $\mathrm{Cs}^{+}$concentrations in plants (Figs 1 and 7). Mathematical modelling and biochemical characterization of the yeast mutant reveals that $\mathrm{Cs}^{+}$sequestration to the vacuole is strongly compromised.

The specific effect of the loss of Sec22p on $\mathrm{Cs}^{+}$uptake is further supported by the different uptake time courses of mutants constricting plasma membrane cation influx or efflux. In addition, these experiments under high-affinity conditions clearly confirm the suspected role of Trk1p and Trk $2 p$ in $\mathrm{Cs}^{+}$influx across the plasma membrane 8,24 and, conversely, the impact of Ena1-4p-driven cation transport in $\mathrm{Cs}^{+}$extrusion from the cells. The $\mathrm{Cs}^{+}$uptake time courses show an interesting biphasic behaviour with an initial plateau for both wild-type and sec22 4 mutant cells before further accumulation proceeds. This observation suggests a threshold leading to the onset of further $\mathrm{Cs}^{+}$sequestration to the vacuole. A similar behaviour has been observed for $t r k 1 \Delta$, although the second phase has been delayed, whereas in ena1-4A the initial phase is apparently lacking. Both findings could be in agreement with a lagging $\mathrm{Cs}^{+}$influx in trk1 $1 \Delta$ or a more rapid $\mathrm{Cs}^{+}$accumulation in ena1-4A.

Discrimination against $\mathrm{Cs}^{+}$at the vacuole in $\sec 22 \Delta$ mutants is specific with respect to the essential cation $\mathrm{K}^{+}$. The total $\mathrm{K}^{+}$ concentration and the $\mathrm{Rb}^{+}$compartmentalization have not been different from the wild type, which indicates unchanged vacuolar $\mathrm{K}^{+}$levels. Vacuolar $\mathrm{K}^{+}$concentration was estimated to be about $440 \mathrm{mM}$ for both wild-type and sec22 4 cells based on (i) the relative volumes of the compartments, (ii) the measured total concentration of $\mathrm{K}^{+}$in whole cells (Fig. 1) and (iii) the assumption of a vacuolar partitioning of $\mathrm{K}^{+}$analogous to $\mathrm{Rb}^{+}$ (Fig. 2e). The corresponding cytosolic $\mathrm{K}^{+}$concentration is $\sim 63 \mathrm{mM}$. Furthermore, the specificity of $\mathrm{Cs}^{+}$sequestration to the vacuole is supported by the consideration that even minor changes in the vacuolar $\mathrm{K}^{+}$concentration of $\sec 22 \Delta$ would substantially decrease the total $\mathrm{K}^{+}$level (which has not been observed) provided that the cytosolic $\mathrm{K}^{+}$homeostasis must be preserved to retain a wild-type-like growth and viability in the $\sec 22 \Delta$ mutant $^{26}$.

In contrast to our findings, Fell et al. ${ }^{27}$ had also suggested an effect on $\mathrm{K}^{+}$homeostasis in $\sec 22 \Delta$ based on an attenuated $\mathrm{Rb}^{+}$ accumulation in the early phase of an uptake experiment in nutrient-deficient medium. An altered $\mathrm{K}^{+}$homeostasis was shown to affect the sensitivity to cationic drugs ${ }^{28}$ and thus could be also related to the $\mathrm{Cs}^{+}$phenotype of $\sec 22 \Delta$. However, in contrast to nutrient-deficient medium, the early uptake time course of $\mathrm{Rb}^{+}$is identical for wild type and $\sec 22 \Delta$ in YPD-rich medium (Supplementary Fig. S6) and the steady-state $\mathrm{Rb}^{+}$and $\mathrm{K}^{+}$concentrations are not affected either (see above).

Sec22p/SEC22 seems to be essential for the uptake and sequestration of $\mathrm{Cs}^{+}$in the wild type, as its loss of function leads to specifically reduced $\mathrm{Cs}^{+}{ }^{+}$uptake in yeast and Arabidopsis. The SNARE Sec22p has been implicated in diverse aspects of protein targeting and autophagy (see the first section of text). Sec22p's classical role as a v-SNARE is in the early anterograde vesicle transport ${ }^{29}$. Results of this work suggest a further link to vacuoles. A direct involvement of the ER-/Golgi-resident Sec22p to vacuolar membranes has been indicated by the fusion of proteoliposomes carrying the R-SNARE Sec22p and vacuolar Qabc-SNAREs. Although the R-SNARE contributes little to fusion specificity and the in vivo relevance has not been studied, this work demonstrates the biophysical ability of Sec22p to interact with vacuolar membranes ${ }^{30}$. Another link to vacuolar functions is provided by the co-responsiveness of Sec22 and Vma22 in the yeast transcriptome ${ }^{31}$. The ER-resident Vma22p is required for assembly of the V-ATPase, which acidifies the vacuolar lumen ${ }^{32}$. Diminished V-ATPase activity results in increased $\mathrm{pH}$ sensitivity and in repressed cation uptake into the vacuole $^{33}$. However, sec22 4 exhibits only weak $\mathrm{pH}$ sensitivity in comparison with vma224 and the V-ATPase subunit mutant vma2d (Fig. 3e) ${ }^{32,34}$. This observation suggests that the sec $22 \Delta$ $\mathrm{Cs}^{+}$phenotype is not owing to a disturbance of vacuolar $\mathrm{pH}$, which is also in agreement with the unchanged $\mathrm{K}^{+}$and $\mathrm{Rb}^{+}$ homeostasis in the SNARE mutant (Fig. 1).

Therefore, Sec22p apparently has a more specialized, non-redundant role affecting the specificity of $\mathrm{Cs}^{+}$deposition to vacuole. Although the detailed molecular mechanism remains obscure, with regard to the known functions of Sec $22 \mathrm{p}$ and its potential additional link to the vacuole, it may be involved in targeting transporters or transport specificity-modulating proteins to alter the efficacy of cation sequestration to the vacuole. Potential targets to be altered at the tonoplast are the $\mathrm{H}^{+} /$cation exchange proteins Vnxlp and Nhx1 $\mathrm{p}^{35-37}$. In addition, the loss of $\sec 22 \Delta$ could lead to mistargeting of such proteins. Recently, the partial mistargeting of plasma membrane Trklp to a yet undetermined intracellular compartment in the sec $22 \Delta$ mutant background has been reported ${ }^{27}$.

The successful transfer of the $\mathrm{Cs}^{+}$-discriminative phenotype from the unicellular yeast model to a higher plant has implications for possible strategies towards breeding 'safer crops'. 
Although the Arabidopsis SEC22 is essential for proliferation ${ }^{18}$, this work shows that its specific loss of function in vegetative tissue allowed for wild-type-like growth and development, yet reducing $\mathrm{Cs}^{+}$accumulation (Figs 6 and 7). Therefore, an organ-specific suppression of SEC22 could reduce the entry of radiocaesium into the food chain, which could be also employed in conjunction with other approaches, such as manipulation of $\mathrm{K}^{+}$-transporter specificity or agricultural measures like $\mathrm{K}^{+}$-rich fertilization ${ }^{5}$. The conservation of SEC22 homologues in crop species supports such a strategy.

\section{Methods}

Chemicals. All chemicals were purchased at the highest available grade from Sigma (Germany), Merck (Germany), VWR (Germany) or Serva (Germany). Radiochemicals were obtained from AEA Technology (Germany), GE Healthcare (Germany) or Hartmann Analytics (Germany).

Yeast strains and growth conditions. Mutant strains sec 224 , vps354, apl44 and aps3 4 are isogenic to BY4741 (MATa; his2A1; leu2A0; met15 $\Delta 0$; ura3 $\Delta 0$ ) and were obtained from EUROSCARF (Institute of Molecular Biosciences, University of

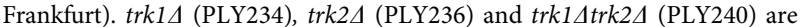
isogenic to PLY232 (MATa; his34200 leu2-3,112 trp14901 ura3-52 suc249) (ref. 24). ena1-44 (G-19) is isogenic to W303.1 (ref. 23). Yeast transformation was performed by addition of $500 \mathrm{ng}$ plasmid DNA to $75 \mu \mathrm{l}$ of exponentially grown yeast cells permeabilized by lithium acetate ${ }^{38}$. A $3 \mathrm{~kb}$ genomic fragment encompassing the yeast Sec22 gene was amplified with primers SEC22coXmalfw and SEC22coHindIIIrv (Supplementary Table S5) and inserted into the plasmid Yep352 after restriction with Xma I and Hin dIII for complementation of sec224 (ref. 39). For complementation of yeast sec224 with Arabidopsis SEC22 (At1g11890), the open reading frame was amplified using the oligonucleotides SEC22fwClaI and SEC22revNotI (Supplementary Table S5) and cloned into the vector pCM $189^{40}$ after restriction with Cla I and Not I, which allowed doxycyclinrepressible expression. Yeast cells were grown on YPD medium, $\mathrm{pH} 6.0$ at $30^{\circ} \mathrm{C}$, if not noted otherwise ${ }^{41}$. The mutants $\operatorname{trk} 1 \Delta, \operatorname{trk} 2 \Delta$ and $\operatorname{trk} 1 \Delta \operatorname{trk} 2 \Delta$, as well as their corresponding wild-type strains, were grown in YPD supplemented with additional $100 \mathrm{mM} \mathrm{KCl}$.

Yeast caesium and rubidium uptake assays. $\mathrm{Cs}^{+}$accumulation assays in 96well MultiScreen HTS plates (Millipore, Germany) were performed using $1 \times 10^{7}$ cells per well in $200 \mu$ l. Cells were incubated in YPD-rich medium, which was supplied with $50 \mu \mathrm{M}$ 5-fluorouracil (5-FU) $4 \mathrm{~h}$ before the start of tracer incubation. This caused growth and cell division arrest without affecting the viability of yeast, in accordance with literature ${ }^{42}$. After washing with $\mathrm{H}_{2} \mathrm{O}$, cells were resuspended in $100 \mu \mathrm{l}$ YPD plus $50 \mu \mathrm{M} 5$-FU. After $1 \mathrm{~h}$ regeneration, an equal amount of YPD supplemented with $50 \mu \mathrm{M} 5$ - $\mathrm{FU}$ and $100 \mu \mathrm{M} \mathrm{CsCl}$ containing $4 \mathrm{kBq} \mathrm{ml}^{-1}{ }^{134} \mathrm{Cs}$ was added. The plates were incubated at $30^{\circ} \mathrm{C}$ on a shaker at 100 r.p.m. Assays were stopped by washing the cells twice before $\gamma$-spectrometric analysis. This experimental setup allowed quasi-constant uptake conditions, as the $50 \mu \mathrm{M}$ external $\mathrm{Cs}^{+}$was at most depleted to $44 \mu \mathrm{M}$. A similar approach was followed for the determination of the $\mathrm{Rb}^{+}$content after $18 \mathrm{~h}$ using $50 \mu \mathrm{M} \mathrm{RbCl}$ containing $10 \mathrm{kBq} \mathrm{ml}^{-186} \mathrm{Rb}$ as a radioactive tracer. In addition, an initial phase of $\mathrm{Rb}^{+}$ accumulation in wild-type BY4741 and sec22 4 were performed in nutrient-limited conditions (50 mM HEPES Tris, pH 7.0 supplied with $2 \%$ glucose) without the addition of 5-FU in comparison with rich medium.

For an efflux experiment, yeast cells incubated in $50 \mu \mathrm{M}{ }^{134} \mathrm{Cs}$ tracer-containing YPD containing $50 \mu \mathrm{M}$ of 5 -FU were harvested after $18 \mathrm{~h}$ and washed twice with tracer-free medium. Cells were incubated in tracer-free medium containing $50 \mu \mathrm{M}$ $\mathrm{CsCl}$ at $30^{\circ} \mathrm{C}$ and analysed at defined time points as cells above.

Sensitivity analysis of yeast strains. For cation toxicity tests, yeast cells were replica plated on YPD plates supplemented with different concentrations of $\mathrm{NaCl}$, $\mathrm{KCl}$ and $\mathrm{CsCl}$. For testing $\mathrm{pH}$ sensitivity, a dilution series of overnight cultures $\left(\mathrm{OD}_{600}=0.8-1.0\right)$ was grown on selective YPD plates with different $\mathrm{pH}$, adjusted with $20 \mathrm{mM}$ MES-NaOH (pH 5.5 and 6.5) or $20 \mathrm{mM}$ HEPES- $\mathrm{NaOH}$ (pH 7.5 and 8.0).

Isolation of intact vacuoles to analyse $\mathbf{C s}^{+}$partitioning. Vacuoles were isolated by a stepwise Ficoll density gradient from spheroplasts obtained from 11 tracerladen cells $\left(\mathrm{OD}_{600}=0.8\right)(\mathrm{refs} 41,43,44)$. Yeast cells had been incubated at $30^{\circ} \mathrm{C}$ for $18 \mathrm{~h}$ in YPD containing $50 \mu \mathrm{M} 5-\mathrm{FU}$ with $50 \mu \mathrm{M} \mathrm{CsCl}$ or RbCl, labelled with $50 \mathrm{kBq} \mathrm{l}^{-1}{ }^{134} \mathrm{Cs}$ or $500 \mathrm{kBq} l^{-186} \mathrm{Rb}$, respectively. After enzymatic cell wall digestion, all steps were performed at $0^{\circ} \mathrm{C}$ to reduce a potential loss of $\mathrm{Cs}^{+}$. Cells were osmotically lysed by Dounce homogenization in $10 \mathrm{mM}$ Tris-MES, pH 6.9, $12 \%$ Ficoll, $0.1 \mathrm{mM} \mathrm{MgCl}_{2}$ and $500 \mathrm{U} \mathrm{ml}^{-1}$ protease inhibitor cocktail (Sigma, Germany). After ultracentrifugation $(30 \mathrm{~min}, 50,000 \mathrm{~g}$ ), the pellet was retained as fraction 1 . The floating material was isolated and overlaid with 8 and $4 \%$ Ficoll for another centrifugation $(45 \mathrm{~min}, 50,000 \mathrm{~g}$ ). The pellet (fraction 2) and the floating vacuolar fraction (fraction 3 ) were collected. $\alpha$-mannosidase activity in ${ }^{134} \mathrm{Cs}$ tracer-laden cell lysates was determined in $2 \mathrm{ml}$ aliquots and the lysates were diluted to match the enzyme activity of the isolated vacuoles in a $6 \mathrm{ml}$ volume.

Enzymatic tests for yeast cell fractionation. Marker enzyme assays were used to characterize the fractions obtained by density gradient fractionation (Supplementary Fig. S4). All fractions were adjusted to the same volume $(500 \mu \mathrm{l})$ before aliquots were analysed. Spheroplasts were used as whole-cell reference. All activities refer to equivalent portions of the individual fractions. Vanadatesensitive plasma membrane ATPase activity was quantified by the vanadatesensitive release of phosphate from ATP in the presence of $5 \mathrm{mM}$ sodium azide $^{45,46}$. The peroxisomal marker catalase $\mathrm{A}$ was assayed by the titanium oxysulfate method ${ }^{47,48}$. NADPH cytochrome $c$ reductase was used as an ER marker based on the reduction of cytochrome $\mathrm{c}$ in the presence of NADPH and rotenone ${ }^{48}$. The activity of $\alpha-1,6$-mannosyltransferase was assayed as a Golgi marker using GDP- $\left[{ }^{14} \mathrm{C}\right]$-mannose and $\alpha$-1,6-mannobiose as substrates ${ }^{49,50}$. The mitochondrial marker succinate dehydrogenase was assayed by quantifying reduced $p$-iodonitrotetrazolium violet ${ }^{48,51}$. Finally, carboxypeptidase $\mathrm{Y}$ and a-D-mannosidase were employed as markers for the vacuolar lumen and membrane, respectively ${ }^{28,52,53}$. Carboxypeptidase Y activity was based on the release of leucine from N-CBZ-L-Phe- L-Leu. Activity of $\alpha$-D-mannosidase was measured using $p$-nitrophenyl- $\alpha$-D-mannopyranoside as a substrate.

Plant lines and growth conditions. Wild-type control plants were A. thaliana accession Col-0. The T-DNA insertion line SALK_042619 (sec22-3) was obtained from Nottingham Arabidopsis Stock Centre ${ }^{54,55}$ and verified by DNA sequencing. Homozygous insertion lines were selected by PCR (Supplementary Table S5) and characterized by RT-PCR (Fig. 4b and Supplementary Table S4). Plants were grown either in hydroponics after seed surface sterilization ${ }^{14}$ or on a non-fertilized, irrigated soil-sand substrate after stratification for 2 days with $16 \mathrm{~h}$ light $\left(75 \mu \mathrm{mol} \mathrm{m}^{-2} \mathrm{~s}^{-1}\right)$ at 21 to $23^{\circ} \mathrm{C}$.

Complementation of A. thaliana sec22-3. The Arabidopsis SEC22 gene (At1g11890) was reassembled from fragments obtained by PCR with primer combinations (I) PromSecfwXmaI, + PromSecrevClaI, (II) SEC22fwClaI + SEC22revXhoI and (III) TermSecfwXhoI + TermSecrevPstI (Supplementary Table S5) and subsequent restriction digestion (Xma I, Cla I, Xho I or Pst I). These fragments were ligated into vector $\mathrm{pBGW}^{55,56}$ cut by Xma I and Pst I. The correct sequence was verified by DNA sequencing. sec22-3 plants were transformed using the floral dip method with Agrobacterium tumefaciens pGV301/pMP90 containing the $\mathrm{pBGW}$ derivative ${ }^{57}$. A homozygous line carrying a single insertion was used for further analysis.

$\gamma$-Spectrometric analysis of ${ }^{{ }^{134}} \mathbf{C s}$ and ${ }^{86} \mathbf{R b}$. Yeast cells were dissolved in $3 \mathrm{ml}$ $3 \mathrm{M} \mathrm{HNO}_{3}$ before $\gamma$-spectrometric analysis with 60 min counting in a Wallac WIZARD 1480 (Perkin Elmer, Germany) based on the spectral peaks for ${ }^{134} \mathrm{Cs}$ $(605$ and $796 \mathrm{keV})$ and ${ }^{86} \mathrm{Rb}(1077 \mathrm{keV})$. Yeast vacuolar fractions were analysed in $6 \mathrm{ml}$ of the isolated fraction. For Arabidopsis samples, at least seven 20-day-old plants from hydroponic cultures supplemented with $5 \mu \mathrm{M} \mathrm{CsCl}$ containing

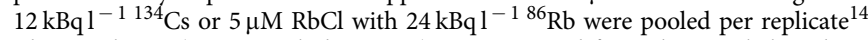
The aerial part (rosette including stem) was separated from the root below the hypocotyl. The material was washed once with water, dried briefly on tissue paper, resuspended in $3 \mathrm{ml} \mathrm{H}_{2} \mathrm{O}$ and analysed.

Determination of non-labelled cation concentrations. Yeast cultures were shaken $\left(30^{\circ} \mathrm{C}\right.$; 100 r.p.m.) for $18 \mathrm{~h}$ in $50 \mathrm{ml}$ YPD containing $50 \mu \mathrm{M}$ 5-FU. Cells $\left(\mathrm{OD}_{600} \approx 0.8\right)$ were collected on $45 \mu \mathrm{m}$ filters and dissolved in $3 \mathrm{ml}$ of $30 \% \mathrm{HNO}_{3}$ at $60^{\circ} \mathrm{C}$ overnight. After a threefold dilution with $\mathrm{H}_{2} \mathrm{O}, 5 \mathrm{ml}$ was analysed using inductively coupled plasma atomic emission spectrometry (Optima 7300, Perkin Elmer, Germany) equipped with a seaspray nebulizer fitting to a cyclon spray chamber (AHF Analysentechnik, Germany). The following elemental emission lines were measured: $\mathrm{Ca}^{2+}: 317.933 \mathrm{~nm} ; \mathrm{K}^{+}: 766.490 \mathrm{~nm} ; \mathrm{Mg}^{2+}: 279.077 \mathrm{~nm}$; and $\mathrm{Na}^{+}: 589.592 \mathrm{~nm}$. Concentrations were determined by external calibration. Arabidopsis roots and leaves from at least eight rosettes or root systems were pooled per sample. Cations were determined by atomic emission spectrometry as above from $2 \mathrm{mg}$ freeze-dried roots or rosette leaves.

Microscopy. Microscopic analyses were performed with an Olympus BX61 equipped with software Cell ${ }^{\star} \mathrm{P}$ (Olympus, Europe). Yeast cells and vacuoles were counted in a Neubauer-type haemocytometer. Cellular and vacuolar volumes were determined after staining cells $\left(\mathrm{OD}_{600}<1.0\right)$ with $15 \mu \mathrm{M}$ SynaptoRed $\mathrm{C} 2$ (=FM4-64) (Biotium, CA, USA; $525 \mathrm{~nm}$ excitation, $647 \mathrm{~nm}$ emission), which was also used as viability indicator ${ }^{58}$. The cellular $(35 \mathrm{fl})$ and vacuolar $(9 \mathrm{fl})$ volumes for wild type under our experimental conditions are in accordance with literature ${ }^{59}$. 


\section{References}

1. Alexakhin, R. M., Fesenko, S. V. \& Sanzharova, N. I. Serious radiation accidents and the radiological impact on agriculture. Radiat. Prot. Dosim. 64, 37-42 (1996).

2. Yasunari, T. J. et al. Cesium-137 deposition and contamination of Japanese soils due to the Fukushima nuclear accident. Proc. Natl Acad. Sci. USA 108, 19530-19534 (2011).

3. Taylor, D. M. \& Gillis, T. M. Correlation of biokinetic behaviour and physicochemical parameters within chemical families: alkali metals and lanthanides. Radiat. Prot. Dosimetry 53, 183-186 (1994).

4. Shaw, G., Hewamanna, R., Lillywhite, J. \& Bell, J. N. B. Radiocaesium uptake and translocation in wheat with reference to the transfer factor concept and ion competition effects. J. Environ. Radioact. 16, 167-180 (1992).

5. White, P. J., Wiesel, L. \& Broadley, M. R. Ion Channels and Plant Stress Responses Signaling and Communication in Plants (eds Demidchik, V. \& Maathuis, F.) 47-67 (Springer-Verlag, 2010).

6. Zhu, Y. G. \& Smolders, E. Plant uptake of radiocaesium: a review of mechanisms, regulation and application. J. Exp. Bot. 51, 1635-1645 (2000).

7. White, P. J. et al. Selecting plants to minimise radiocaesium in the food chain. Plant Soil 249, 177-186 (2003).

8. Avery, S. V. Caesium accumulation by microorganisms: uptake mechanisms, cation competition, compartmentalization and toxicity. J. Ind. Microbiol. 14, 76-84 (1995).

9. Hampton, C. R. et al. Cesium toxicity in Arabidopsis. Plant Physiol. 136, 3824-3837 (2004).

10. Sheahan, J. J., Ribeiro-Neto, L. \& Sussman, M. R. Cesium-insensitive mutants of Arabidopsis thaliana. Plant J. 3, 647-656 (1993).

11. Broadley, M. R. \& White, P. J. Some elements are more equal than others: soil-to-plant transfer of radiocaesium and radiostrontium, revisited. Plant Soil 355, 23-27 (2012)

12. Vinichuk, M., Taylor, A. F., Rosén, K. \& Johanson, K. J. Accumulation of potassium, rubidium and caesium ${ }^{133} \mathrm{Cs}$ and ${ }^{137} \mathrm{Cs}$ in various fractions of soil and fungi in a Swedish forest. Sci. Total Environ. 408, 2543-2548 (2010).

13. Payne, K. A. et al. Natural genetic variation in caesium (Cs) accumulation by Arabidopsis thaliana. New Phytol. 162, 535-548 (2004).

14. Kanter, U., Hauser, A., Michalke, B., Dräxl, S. \& Schäffner, A. R. Caesium and strontium accumulation in shoots of Arabidopsis thaliana: genetic and physiological aspects. J. Exp. Bot. 61, 3995-4009 (2010).

15. Heuck, S., Gerstmann, U. C., Michalke, B. \& Kanter, U. Genome-wide analysis of caesium and strontium accumulation in Saccharomyces cerevisiae. Yeast 27, 817-835 (2010).

16. Liu, Y. \& Barlowe, C. Analysis of Sec22p in endoplasmic reticulum/Golgi transport reveals cellular redundancy in SNARE protein function. Mol. Biol. Cell 13, 3314-3324 (2002).

17. Nair, U. et al. SNARE proteins are required for macroautophagy. Cell 146, 290-302 (2011)

18. El-Kasmi, F. et al. Arabidopsis SNARE protein SEC22 is essential for gametophyte development and maintenance of Golgi-stack integrity. Plant J. 66, 268-279 (2011)

19. Cabrera, E., Álvarez, M. C., Martín, Y., Siverio, J. M. \& Ramos, J. K(+ ) uptake systems in the yeast Hansenula polymorpha. Transcriptional and posttranslational mechanisms involved in high-affinity $\mathrm{K}(+)$ transporter regulation. Fungal. Genet. Biol. 49, 755-763 (2012).

20. Yoshihisa, T. \& Anraku, Y. A novel pathway of import of alpha-mannosidase, a marker enzyme of vacuolar membrane, in Saccharomyces cerevisiae. J. Biol. Chem. 265, 22418-22425 (1990).

21. Perkins, J. \& Gadd, G. Caesium toxicity, accumulation and intracellular localization in yeasts. Mycol. Res. 97, 717-724 (1993).

22. Jorgensen, P., Nishikawa, J. L., Breitkreutz, B. J. \& Tyers, M. Systematic identification of pathways that couple cell growth and division in yeast. Science 297, 395-400 (2002).

23. Banuelos, M. A., Klein, R. D., Alexander-Bowman, S. J. \& Rodríguez-Navarro, A. A potassium transporter of the yeast Schwanniomyces occidentalis homologous to the Kup system of Escherichia coli has a high concentrative capacity. EMBO J. 14, 3021-3027 (1995).

24. Bertl, A. et al. Characterization of potassium transport in wild-type and isogenic yeast strains carrying all combinations of trk1, trk2 and tok1 null mutations. Mol. Microbiol. 47, 767-780 (2003).

25. Chatre, L., Brandizzi, F., Hocquellet, A., Hawes, C. \& Moreau, P. Sec22 and Memb11 are v-SNAREs of the anterograde endoplasmic reticulum-Golgi pathway in tobacco leaf epidermal cells. Plant Physiol. 139, 1244-1254 (2005).

26. Ariño, J., Ramos, J. \& Sychrová, H. Alkali metal cation transport and homeostasis in yeasts. Microbiol. Mol. Biol. Rev. 74, 95-120 (2010).

27. Fell, G. L., Munson, A. M., Croston, M. A. \& Rosenwald, A. G. Identification of yeast genes involved in $\mathrm{K}^{+}$homeostasis: loss of membrane traffic genes affects $\mathrm{K}^{+}$uptake. G3 (Bethesda) 1, 43-56 (2011).
28. Barreto, L. et al. A genomewide screen for tolerance to cationic drugs reveals genes important for potassium homeostasis in Saccharomyces cerevisiae. Eukaryot. Cell 10, 1241-1250 (2011).

29. Stevens, T., Esmon, B. \& Schekman, R. Early stages in the yeast secretory pathway are required for transport of carboxypeptidase $\mathrm{Y}$ to the vacuole. Cell 30, 439-448 (1982).

30. Izawa, R., Onoue, T., Furukawa, N. \& Mima, J. Distinct contributions of vacuolar Qabc- and R-SNARE proteins to membrane fusion specificity. J. Biol. Chem. 287, 3445-3453 (2012).

31. Steinhauser, D., Usadel, B., Luedemann, A., Thimm, O. \& Kopka, J. CSB.DB: a comprehensive systems-biology database. Bioinformatics 20, 3647-3651 (2004).

32. Nelson, H. \& Nelson, N. Disruption of genes encoding subunits of yeast vacuolar $\mathrm{H}(+)$-ATPase causes conditional lethality. Proc. Natl Acad. Sci. USA 87, 3503-3507 (1990).

33. Graham, L. A., Flannery, A. R. \& Stevens, T. H. Structure and assembly of the yeast V-ATPase. J. Bioenerg. Biomembr. 35, 301-312 (2003).

34. Liu, Q., Kane, P. M., Newman, P. R. \& Forgac, M. Site-directed mutagenesis of the yeast V-ATPase B subunit (Vma2p). J. Biol. Chem. 271, 2018-2022 (1996).

35. Cagnac, O., Aranda-Sicilia, M. N., Leterrier, M., Rodríguez-Rosales, M. P. \& Venema, K. Vacuolar cation/ $\mathrm{H}^{+}$antiporters of Saccharomyces cerevisiae. J. Biol. Chem. 285, 33914-33922 (2010).

36. Gaxiola, R. A. et al. The Arabidopsis thaliana proton transporters, AtNhx1 and Avp1, can function in cation detoxification in yeast. Proc. Natl Acad. Sci. USA 96, 1480-1485 (1999).

37. Leidi, E. O. et al. The AtNHX1 exchanger mediates potassium compartmentation in vacuoles of transgenic tomato. Plant J. 61, 495-506 (2010).

38. Gietz, R. D., Schiestl, R. H., Willems, A. R. \& Woods, R. A. Studies on the transformation of intact yeast cells by the LiAc/SS-DNA/PEG procedure. Yeast 11, 355-360 (1995).

39. Hill, J. E., Myers, A. M., Koerner, T. J. \& Tzagoloff, A. Yeast/E. coli shuttle vectors with multiple unique restriction sites. Yeast 2, 163-167 (1986).

40. Garí, E., Piedrafita, L., Aldea, M. \& Herrero, E. A set of vectors with a tetracycline-regulatable promoter system for modulated gene expression in Saccharomyces cerevisiae. Yeast 13, 837-848 (1997).

41. Sherman, F. Getting started with yeast. Methods Enzymol. 194, 3-21 (1991).

42. Poletto, N. P., Rosado, J. O. \& Bonatto, D. Evaluation of cytotoxic and cytostatic effects in Saccharomyces cerevisiae by poissoner quantitative drop test. Basic Clin. Pharmacol. Toxicol. 104, 71-75 (2009).

43. Ohsumi, Y. \& Anraku, Y. Active transport of basic amino acids driven by a proton motive force in vacuolar membrane vesicles of Saccharomyces cerevisiae. J. Biol. Chem. 256, 2079-2082 (1981).

44. Kipper, J., Strambio-de-Castillia, C., Suprapto, A. \& Rout, M. P. Isolation of nuclear envelope from Saccharomyces cerevisiae. Methods Enzymol. 351, 394-408 (2002).

45. Serrano, R. Characterization of the plasma membrane ATPase of Saccharomyces cerevisiae. Mol. Cell. Biochem. 22, 51-63 (1978).

46. Bowman, B. J. \& Slayman, C. W. The effects of vanadate on the plasma membrane ATPase of Neurospora crassa. J. Biol. Chem. 254, 2928-2934 (1979).

47. Lück, H. Methods of Enzymatic Analysis. (ed. Bergmeyer, H. U.) 885-894 (Academic Press, 1963).

48. Rieder, S. E. \& Emr, S. D. Isolation of subcellular fractions from the yeast Saccharomyces cerevisiae. Curr. Protoc. Cell. Biol. Chapter 3 Unit 3.8 (2001).

49. Nakajima, T. \& Ballou, C. E. Yeast manno-protein biosynthesis: solubilization and selective assay of four mannosyltransferases. Proc. Natl Acad. Sci. USA 72, 3912-3916 (1975).

50. Jelinek-Kelly, S., Akiyama, T., Saunier, B., Tkacz, J. S. \& Herscovics, A. Characterization of a specific alpha-mannosidase involved in oligosaccharide processing in Saccharomyces cerevisiae. J. Biol. Chem. 260, 2253-2257 (1985).

51. Ackrell, B. A., Kearney, E. B. \& Singer, T. P. Mammalian succinate dehydrogenase. Methods Enzymol. 53, 466-483 (1978).

52. Sarry, J. E. et al. Analysis of the vacuolar luminal proteome of Saccharomyces cerevisiae. FEBS J. 274, 4287-4305 (2007).

53. Opheim, D. J. Alpha-D-mannosidase of Saccharomyces cerevisiae. Characterization and modulation of activity. Biochim. Biophys. Acta 524, 121-130 (1978).

54. Scholl, R. L., May, S. T. \& Ware, D. H. Seed and molecular resources for Arabidopsis. Plant Physiol. 124, 1477-1480 (2000).

55. Alonso, J. M. et al. Genome-wide insertional mutagenesis of Arabidopsis thaliana. Science 301, 653-657 (2003).

56. Karimi, M., Inzé, D. \& Depicker, A. GATEWAY vectors for Agrobacteriummediated plant transformation. Trends Plant Sci. 7, 193-195 (2002).

57. Clough, S. J. \& Bent, A. F. Floral dip: a simplified method for Agrobacteriummediated transformation of Arabidopsis thaliana. Plant J. 16, 735-743 (1998).

58. Vida, T. A. \& Emr, S. D. A new vital stain for visualizing vacuolar membrane dynamics and endocytosis in yeast. J. Cell. Biol. 128, 779-792 (1995). 
59. Wiemken, A. \& Dürr, M. Characterization of amino acid pools in the vacuolar compartment of Saccharomyces cerevisiae. Arch. Microbiol. 101, 45-57 (1974).

60. Smyth, D. R., Bowman, J. L. \& Meyerowitz, E. M. Early flower development in Arabidopsis. Plant Cell 2, 755-767 (1990).

\section{Acknowledgements}

We thank Katja Lammens and Jörg Durner for useful discussion, and Günther Bahnweg and Antje von Schaewen for critical reading of the manuscript, as well as three anonymous reviewers for valuable comments. Monika Röhmuß, Birgit Geist and Wolfgang Schultz contributed technical support; and Elisabeth Becker supported the vacuole isolation experiments. The authors wish to thank Adam Bertl (Technische Universität Darmstadt) and Alonso Rodríguez-Navarro (Universidad Politécnica de Madrid) for providing yeast strains $t r k 1 \Delta, t r k 2 \Delta, t r k 1 \Delta t r k 2 \Delta$ and ena1 $\Delta$, respectively. This project was supported by the German Federal Ministry of Education and Research (BMBF) with the contract $02 \mathrm{NUK} 002 \mathrm{~B}$. The contents are solely the responsibility of the authors.

\section{Author contributions}

S.D., U.K., A.R.S. and J.M. designed the research; S.D., J.M. and W.B.L. conducted the research; J.M., W.B.L., H.S., B.A.H. and S.D. analysed the data; B.M. and J.T. contributed analytical tools; and S.D. and A.R.S. wrote the paper.

\section{Additional information}

Supplementary Information accompanies this paper at http://www.nature.com/

naturecommunications

Competing financial interests: The authors declare no competing financial interests.

Reprints and permission information is available online at http://npg.nature.com/ reprintsandpermissions/

How to cite this article: Dräxl, S. et al. Caesium accumulation in yeast and plants is selectively repressed by loss of the SNARE Sec22p/SEC22. Nat. Commun. 4:2092 doi: $10.1038 /$ ncomms3092 (2013). 